\title{
Effect of Subgrains on the Performance of Mono-Like Crystalline Silicon Solar Cells
}

\author{
Su Zhou, Chunlan Zhou, Wenjing Wang, Yehua Tang, Jingwei Chen, \\ Baojun Yan, and Yan Zhao
}

The Key Laboratory of Solar Thermal Energy and Photovoltaic System, Institute of Electrical Engineering, Chinese Academy of Sciences, Beijing 100190, China

Correspondence should be addressed to Wenjing Wang; wangwj@mail.iee.ac.cn

Received 4 June 2013; Accepted 11 September 2013

Academic Editor: Adel M. Sharaf

Copyright $\odot 2013$ Su Zhou et al. This is an open access article distributed under the Creative Commons Attribution License, which permits unrestricted use, distribution, and reproduction in any medium, provided the original work is properly cited.

The application of Czochralski $(\mathrm{Cz})$ monocrystalline silicon material in solar cells is limited by its high cost and serious lightinduced degradation. The use of cast multicrystalline silicon is also hindered by its high dislocation densities and high surface reflectance after texturing. Mono-like crystalline silicon is a promising material because it has the advantages of both mono- and multicrystalline silicon. However, when mono-like wafers are made into cells, the efficiencies of a batch of wafers often fluctuate within a wide range of $>1 \%$ (absolute). In this work, mono-like wafers are classified by a simple process and fabricated into laser doping selective emitter cells. The effect and mechanism of subgrains on the performance of mono-like crystalline silicon solar cells are studied. The results show that the efficiency of mono-like crystalline silicon solar cells significantly depends on material defects that appear as subgrains on an alkaline textured surface. These subgrains have an almost negligible effect on the optical performance, shunt resistance, and junction recombination but significantly affect the minority carrier diffusion length and quantum efficiency within a long wavelength range. Finally, an average efficiency of $18.2 \%$ is achieved on wafers with hardly any subgrain but with a small-grain band.

\section{Introduction}

Most current industrial solar cells are made of Czochralski $(\mathrm{Cz})$-grown monocrystalline silicon material and cast multicrystalline silicon substrates [1]. However, $\mathrm{Cz}$ monocrystalline silicon material has a high cost and undergoes serious light-induced degradation (LID) of efficiency under sunlight. Defects with very high dislocation densities and high surface reflectance after texturing can limit the application of multicrystalline silicon [2-4]. Mono-like crystalline silicon, which has the advantages of both $\mathrm{Cz}$ and multicrystalline silicon, is fabricated using a $\mathrm{Cz}$ monoseed layer or by optimized growth nucleation during ingot casting $[5,6]$. Recently, these square mono-like crystalline wafers have gained considerable attention because of their low structural defect density, low fabrication cost, and weak LID [7, 8]. Several approaches to improve the quality of mono-like crystalline silicon have been presented [9-11]. However, an important remaining issue is that when mono-like wafers are made into cells, the range of efficiencies of a batch of wafers fluctuates within a wide range of $>1 \%$ (absolute) [12].

This paper aims to explain the abnormal efficiency fluctuation of mono-like wafers. Mono-like wafers were classified by the subgrain content after alkaline texturing and then fabricated into laser doping selective emitter (LDSE) cells. The optical and electrical performances of these cells were analyzed, and several measurements were performed to estimate the effects of subgrains on solar cells. Finally, semimono-like crystalline silicon wafers, which have almost no sub-grain but have a small-grain band, are chosen to prepare LDSE cells to demonstrate the effect of subgrains on cell performance.

\section{Experimental}

All wafers used in this study were commercial grade, $1 \Omega \cdot \mathrm{cm}$, p-type mono-like crystalline $\mathrm{Si}$ wafers with an area of 6 square inches $\left(243.4 \mathrm{~cm}^{2}\right)$ and thickness of $\sim 200 \mu \mathrm{m}$. Wafers 


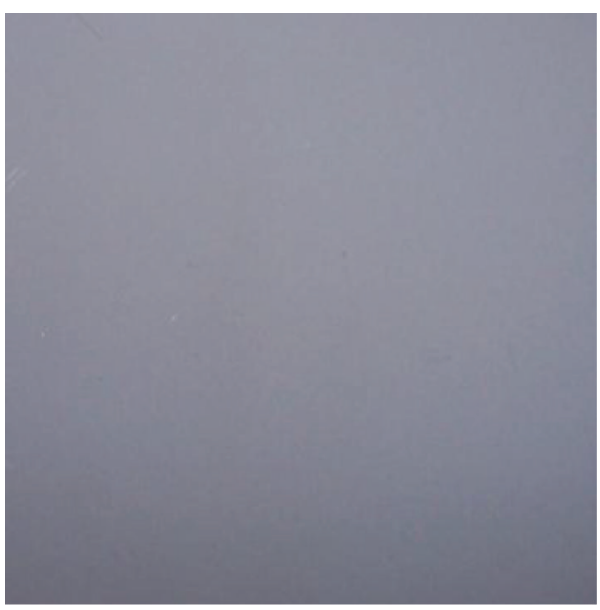

(a)

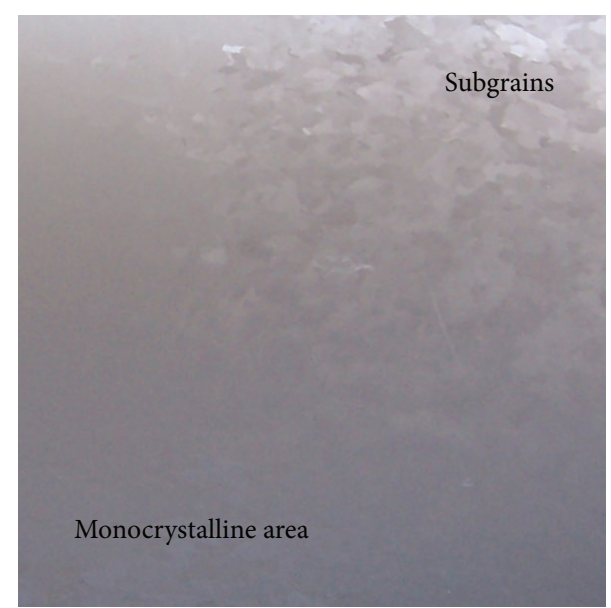

(b)

FIGURE 1: Optical image of a part of the alkaline textured wafer with sub-grain regions: (a) vertical view and (b) with a tilt angle of $45^{\circ}$.

are typically optically perfect and appear like square $\mathrm{Cz}$ monowafers. After texturing in a mixture of $1 \% \mathrm{NaOH}$ and $4 \%$ isopropyl alcohol, some subgrains appeared on some parts of the mono-like wafers, as shown in Figure 1. Figure 1(a) shows an alkaline textured surface like monocrystalline wafer. However, when the image was taken at a tilt angle of $45^{\circ}$, subgrains with an estimated size of 3-7 mm can be observed as shown in Figure 1(b).

According to the content of these subgrains, the wafers were divided into three classes. Wafers with ratios of subgrains area to total wafer area of $<10 \%, \sim 50 \%$, and $>90 \%$ on their surface were defined as grades A, B, and C, respectively. All wafers after alkaline texturing were phosphorus diffused to a sheet resistance of $80 \Omega / \square$ with $\mathrm{POCl}_{3}$ liquid source. An industrial wet chemical etching process was then performed to achieve edge junction isolation. $\mathrm{A} \mathrm{SiN}_{x}$ antireflection coating (ARC) was deposited onto the front surface of the wafers using an industrial remote plasma-enhanced chemical vapor deposition system. Aluminum (Al) paste was then screen printed on the rear surface of the wafers and fired in a belt furnace at $900^{\circ} \mathrm{C}$ to form the back surface field of the cells. Diluted phosphoric acid was spin coated on the $\operatorname{SiN}_{x}$ film. A $532 \mathrm{~nm}$ Q-switched Nd:YAG laser was used to remove the dielectric layer and pattern laser-doping $\mathrm{n}+$ finger patterns on the $n$-type surface simultaneously. Nickel (Ni) and silver (Ag) were then plated onto the patterned fingers by light-induced plating and sintered to form Ni silicate, which provided lowresistance contact.

The surface reflectance of textured and passivated samples and internal quantum efficiency (IQE) of cells within the range of $300 \mathrm{~nm}$ to $1200 \mathrm{~nm}$ were measured using a solar cell spectral response/quantum efficiency measurement system (QEX7, PV Measurement). The electroluminescence (EL) images, light beam-induced current (LBIC), and diffusion length of fabricated solar cells were characterized using an infrared defect inspection tool (ELT C02, ASIC) and tabletop PV measurement system (WT-2000, Semilab). A currentvoltage (I-V) tester was used to obtain both dark and illuminated I-V curves and to assess the electrical performances of the laser-doped $p$-type mono-like crystalline Si solar cells with different sub-grain amounts.

\section{Results and Discussion}

3.1. Optical Performances and IQE. Figure 2 shows an experimental comparison of the percentage reflectance of textured and ARC-coated wafers with the IQE of cells with subgrain and monocrystalline areas within a wavelength range of $300 \mathrm{~nm}$ to $1200 \mathrm{~nm}$. The overall reflectance of sub-grain areas is similar to that of monocrystalline areas, except for a slight increase within the short wavelength range of $300 \mathrm{~nm}$ to $400 \mathrm{~nm}$. The weighted reflectances of sub-grain and monocrystalline areas after ARC coating are $4.03 \%$ and $4.04 \%$, respectively. The similar weighted reflectance means that the subgrains have minimal effect on the light trapping of the pyramid texture. However, as shown in Figure 2, the IQE of cells with sub-grain areas is significantly decreased within the range of $600 \mathrm{~nm}$ to $1100 \mathrm{~nm}$ wavelength compared with the result of monocrystalline areas. According to the deep penetration of long wavelength light in silicon, the reduction of IQE may be attributed to the recombination in silicon substrate. Thus, the recombination rate is likely to be higher in sub-grain areas than in monocrystalline areas, which decreases the IQE of fabricated cells within the long wavelength range under the same light condition.

3.2. Analysis on Solar Cell Parameters. Table 1 compares various cell parameters fabricated by wafers with different sub-grain contents. For each type of silicon wafer, 10 solar cells were fabricated and measured. With increased sub-grain content from $<10 \%$ to $>90 \%$, the cell efficiency decreases from $17.6 \%$ to $16.0 \%$. With increased sub-grain content, the open-circuit voltage $\left(V_{\text {oc }}\right)$ of the cell decreases from $628.9 \mathrm{mV}$ to $615.9 \mathrm{mV}$, and the short-circuit current density $\left(J_{\mathrm{sc}}\right)$ of the cell decreases from $36.87 \mathrm{~mA} / \mathrm{cm}^{2}$ to $34.35 \mathrm{~mA} / \mathrm{cm}^{2}$. The decrease in the efficiency can be attributed to the significant decrements in $V_{\mathrm{oc}}$ and $J_{\mathrm{sc}}$. 


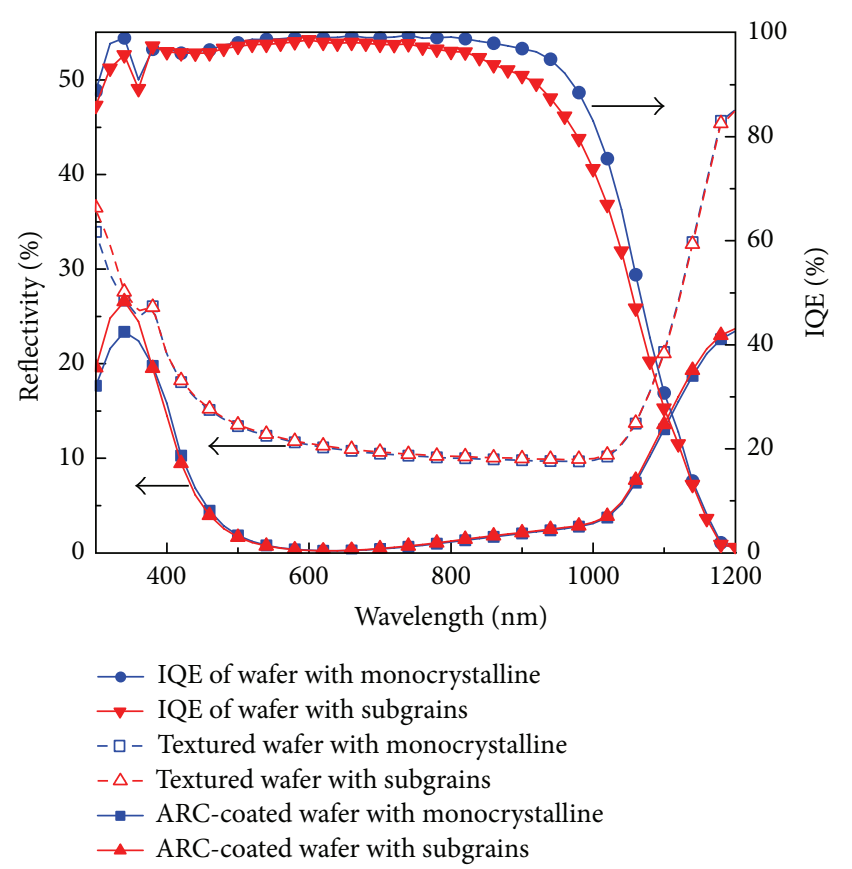

FIGURE 2: Reflectance of textured and ARC-coated wafers and IQE of cells with subgrains and monocrystalline areas.

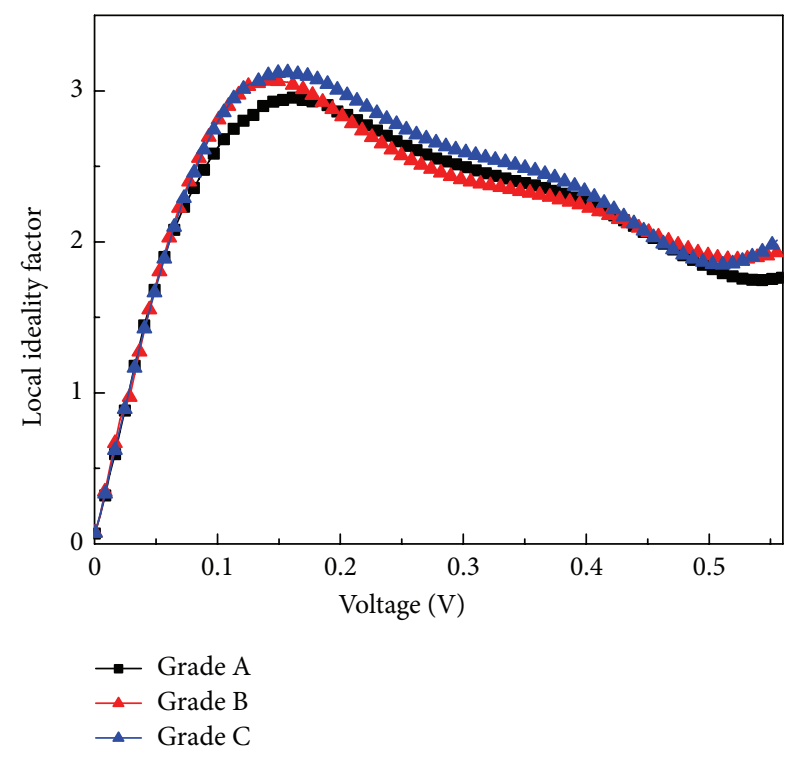

FIgURE 3: Local ideality factor curves derived from the dark $I$ $V$ curves of monocrystalline LD solar cells fabricated on different substrates.

The local ideality factor, $m$, of a solar cell in the dark is given by

$$
m=\frac{1}{V_{T}}\left(\frac{d V}{d \ln (I)}\right),
$$

where $V$ and $I$ are the measured dark voltage and current, respectively, and $V_{T}=0.026 \mathrm{eV}$. The local ideality factors in different voltage regions indicate different mechanisms which
TABLE 1: Average electrical parameters of 10 solar cells fabricated on different substrates.

\begin{tabular}{lcccc}
\hline Grade & $V_{\mathrm{oc}}(\mathrm{mV})$ & $J_{\mathrm{sc}}\left(\mathrm{mA} / \mathrm{cm}^{2}\right)$ & $\mathrm{FF}(\%)$ & Eta $(\%)$ \\
\hline A & $628.9 \pm 1.2$ & $36.9 \pm 0.1$ & $75.8 \pm 0.6$ & $17.6 \pm 0.2$ \\
B & $621.6 \pm 2.3$ & $35.9 \pm 0.2$ & $75.2 \pm 0.4$ & $16.8 \pm 0.2$ \\
C & $615.9 \pm 3.0$ & $34.4 \pm 0.2$ & $75.7 \pm 0.6$ & $16.0 \pm 0.3$ \\
\hline
\end{tabular}

may have an effect on cell performance $[13,14]$. Figure 3 shows the local ideality factor curves derived from the dark $I-V$ curves of mono-like crystalline laser-doping (LD) solar cells fabricated on different substrates. The local ideality factors of different-grade wafers are similar $(>2)$ around the low-voltage region $(<0.4 \mathrm{~V})$, indicating that shunting may have occurred in all these cells. This shunting problem may be caused by insufficient edge isolation. The local ideality factors of different-grade wafers around the medium-voltage region (near the maximum power point) are also similar, indicating that the subgrains hardly affect the formation of localized Schottky contacts. The result shows that the shunting property and metal contact of mono-like crystalline LD solar cells are independent of the subgrains.

3.3. EL Image. Figure 4 shows the EL images of cells fabricated with different sub-grain contents. With increased subgrain content, dark line clusters spread from a small part to almost the entire surface. These dark line clusters indicate a low EL intensity which can be caused by series resistance variations or locally enhanced recombination. These dark line clusters are also closely correlated with subgrains observed on the wafer surface. This finding indicates that these subgrains, which can represent material defects such as grain boundaries and dislocations, play an important role in enhancing series resistance or recombination of minority carriers. Grain boundaries and dislocations are known to be easily generated during casting, and the dislocation density increases from bottom to top of the ingots $[15,16]$. The dislocation density, especially dislocation clusters correlated with subgrains, has been found to affect the recombination of light-generated minority carriers significantly and thus the solar cell efficiencies of cast multicrystalline silicon [17, 18]. Therefore, dislocations caused by sub-grain formation can be inferred to result in the recombination of minority carriers and the dark line clusters found in the EL images.

3.4. Minority Carrier Diffusion Length. Figure 5 shows various spatial distributions of cells with different sub-grain contents. Red represents the regions with a minority carrier diffusion length (MCDL) of $\sim 130 \mu \mathrm{m}$, and black represents those with an MCDL of $\sim 420 \mu \mathrm{m}$. Strong local variations in MCDL can be clearly seen in different regions from Figures 5(a) to 5(c). With increased sub-grain content, the diffusion length significantly decreases and the diffusion length distribution changes from uniform to nonuniform. Moreover, these regions of low diffusion length in Figures 5(b) and 5(c) also correspond with subgrains observed on the wafer surface. These reduced diffusion length regions, which indicate locally enhanced recombination, may lead to 


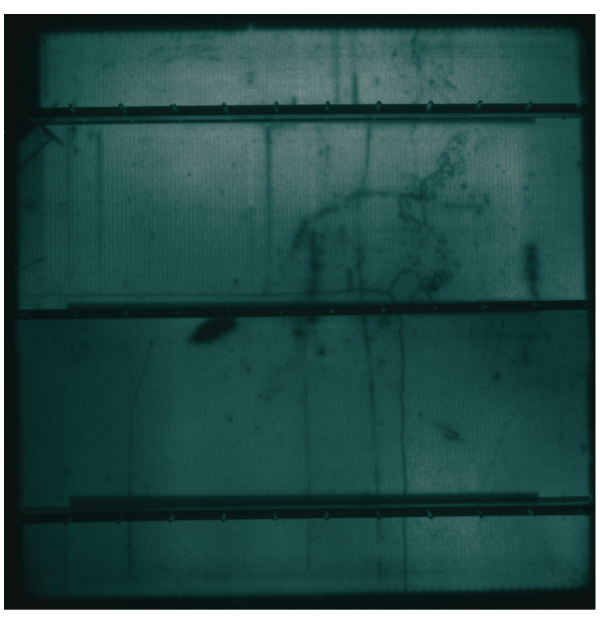

(a)

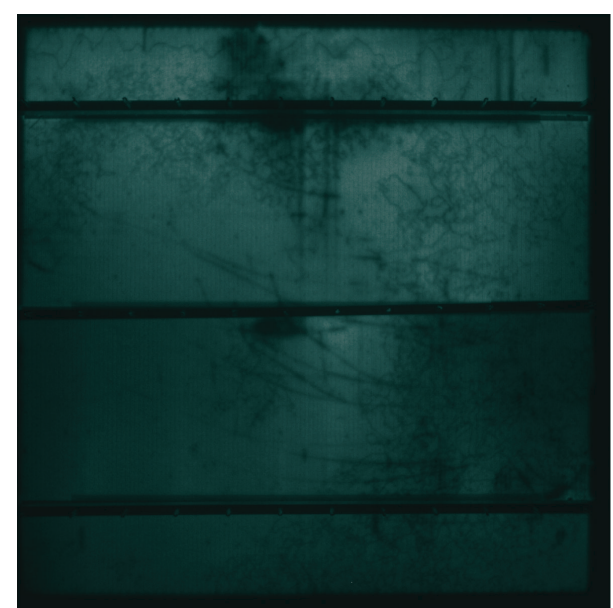

(b)

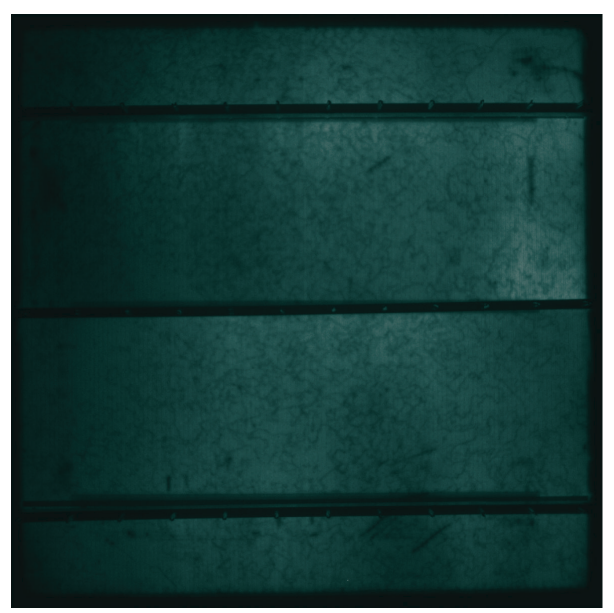

(c)

FIGURE 4: EL images of solar cells fabricated on different substrates: ((a)-(c)) grades A-C, respectively.

decreased $V_{\text {oc }}$. Those longitudinal lines in figures are resulted from fingers of solar cells by blocking the testing laser spot light during the test.

3.5. LBIC Measurement. Further characterizations were performed to determine the influence of subgrains on recombination. The IQE distribution, which was measured by the two-dimensional LBIC method, can represent recombination activity in different regions at different wavelengths of light [19-21]. The IQE distributions measured at 405 and $979 \mathrm{~nm}$ are shown in Figures 6 and 7. The uniform and similar IQE distributions of cells with different sub-grain contents in Figure 5 indicate that the locally enhanced recombination caused by subgrains has hardly any effects on the lightinduced current at $405 \mathrm{~nm}$. The penetration depth of $405 \mathrm{~nm}$ wavelength light is about $500 \mathrm{~nm}$ in crystalline silicon. Therefore, the IQE measured at this wavelength indicates the information of emitter and PN junction. The strong field passivation effect caused by the PN junction and the dominating auger recombination caused by the highly doped $n$-type emitter may result in uniform light-induced current and IQE at $405 \mathrm{~nm}$.

However, the result measured at $979 \mathrm{~nm}$ shows a significant difference. With increased sub-grain content, the IQE significantly decreases, and the IQE distribution changes from uniform to non-uniform. These non-uniform areas in Figure 7 correspond with sub-grain regions. The penetration depth of $979 \mathrm{~nm}$ wavelength light is about $99 \mu \mathrm{m}$ in crystalline silicon. Therefore, the IQE measured at this wavelength indicates information on the bulk material. The locally enhanced recombination caused by defects and grain boundaries shown as subgrains significantly affects the lightinduced current in the bulk silicon.

3.6. Solar Cell Performance of Wafers without Subgrains. To illustrate the effect of subgrains on cell performance, wafers with hardly any sub-grain but with a small-grain band, which means an area with many small grains, were chosen to prepare LDSE cells. Figures $8(\mathrm{a})$ and $8(\mathrm{~b})$ show optical and EL images of fabricated solar cells, respectively. Hardly any 


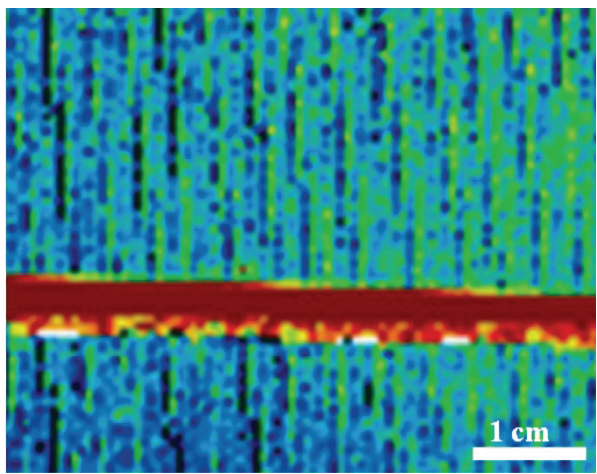

(a)

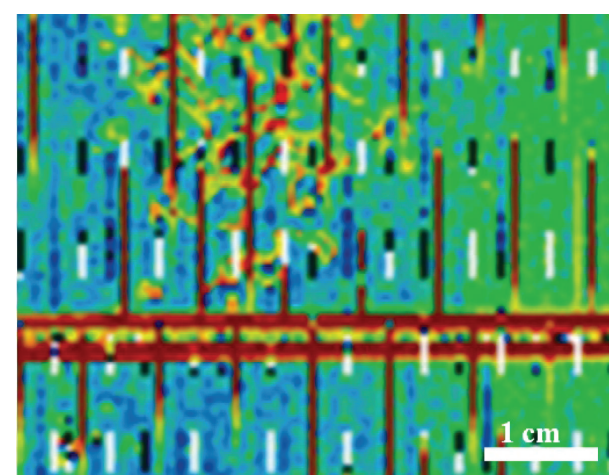

(b)

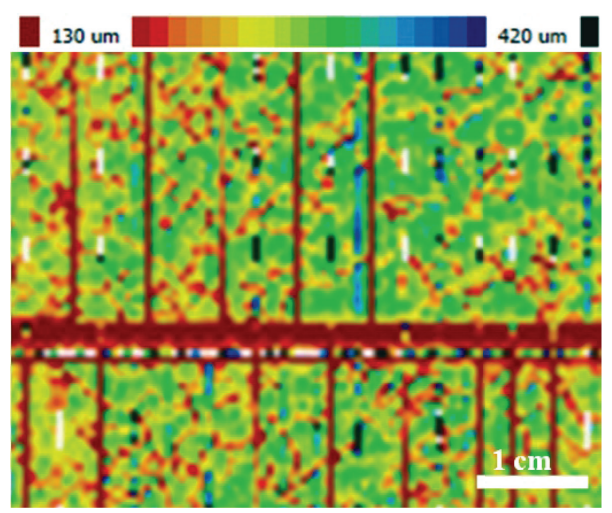

(c)

FiguRE 5: Spatial distribution of minority carrier diffusion length of solar cells fabricated on different substrates: ((a)-(c)) grades A-C, respectively.

TABLE 2: Average electrical parameters of 10 solar cells fabricated on wafers with hardly any sub-grain but with a small-grain band.

\begin{tabular}{lccc}
\hline$V_{\mathrm{oc}}(\mathrm{mV})$ & $J_{\mathrm{sc}}\left(\mathrm{mA} / \mathrm{cm}^{2}\right)$ & $\mathrm{FF}(\%)$ & Eta $(\%)$ \\
\hline $634.1 \pm 1.4$ & $37.2 \pm 0.1$ & $76.9 \pm 0.5$ & $18.2 \pm 0.1$ \\
\hline
\end{tabular}

dark line clusters can be observed in the EL image. The small straight line dark regions are caused by the slight peeling of grid lines. The average electrical performance results are shown in Table 2. As shown in Figure 8(a), the small-grain band becomes a high-reflectivity area after alkaline texturing, leading to more optical loss. Despite the high reflectivity of the small-grain band, $V_{\mathrm{oc}}$ and $J_{\mathrm{sc}}$ of cells with a small-grain band are still higher than that of the grade A mono-like cells which have a ratio of subgrains area to total wafer area of $<10 \%$. Average $V_{\text {oc }}$ increases from $628.9 \mathrm{mV}$ to $634.1 \mathrm{mV}$, and average $J_{\mathrm{sc}}$ increases from $36.9 \mathrm{~mA} / \mathrm{cm}^{2}$ to $37.2 \mathrm{~mA} / \mathrm{cm}^{2}$, respectively. These increments in $V_{\mathrm{oc}}$ and $J_{\mathrm{sc}}$ indicate that the grain boundaries and defects represented by subgrains have more effects on the electrical performance of mono-like solar cells than high-reflectivity small-grain band.

\section{Conclusions}

The application of optically perfect mono-like wafers can be challenging because of abnormal efficiency fluctuations.
This study showed that cell efficiency decreases with increased sub-grain content. The reflectance of monocrystalline and sub-grain areas after texturing and ARC coating is the same. However, the IQE of cells with sub-grain areas significantly decreases within $600 \mathrm{~nm}$ to $1100 \mathrm{~nm}$ compared with monocrystalline areas. The local ideality factor result shows that the shunting property and metal contact of monolike crystalline LD solar cells are independent of subgrains. However, subgrains shown as dark line clusters in the EL image significantly decrease the diffusion length and the IQE at long wavelengths in these regions. This finding indicates that defects caused by subgrains act as the recombination center for minority carriers, degrading the IQE in middleand long-wavelength range and further affecting the solar cell performance. Finally, an average efficiency of $18.2 \%$ was achieved on wafers with hardly any sub-grain but with a small-grain band to indicate that the negative effect of subgrain on cell performance would be more serious than that of small-grain band. This average efficiency also illustrates the promising application potential of mono-like wafers. It can be inferred that higher efficiency would be obtained on the mono-like wafers without any sub-grain areas and smallgrain bands. Thus, defects appeared as subgrains significantly affect cell performance, and dislocations must be eliminated by optimizing the casting process for the industrial application of mono-like crystalline silicon. 


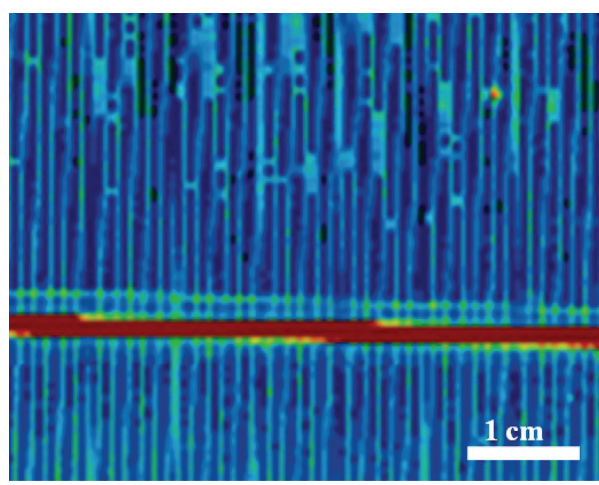

(a)

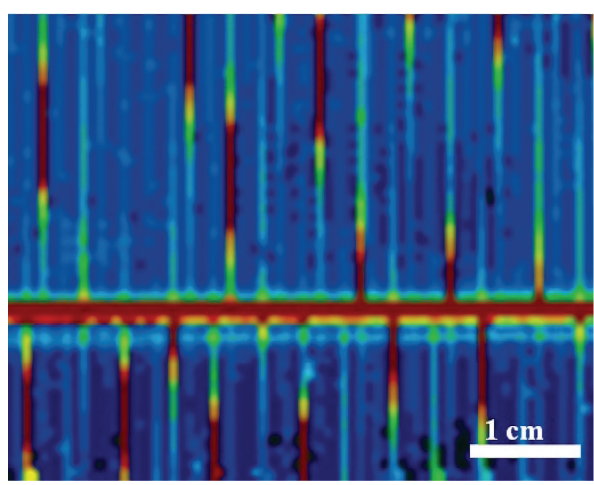

(b)

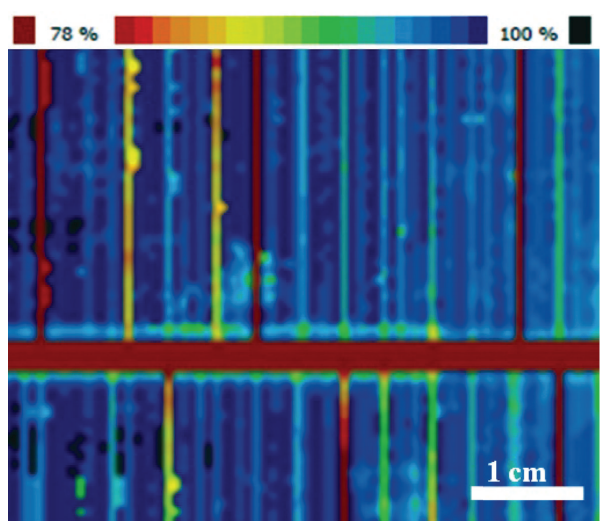

(c)

FIGURE 6: IQE distribution of solar cells fabricated on different substrates at $405 \mathrm{~nm}$ wavelength: ((a)-(c)) grades A-C, respectively.

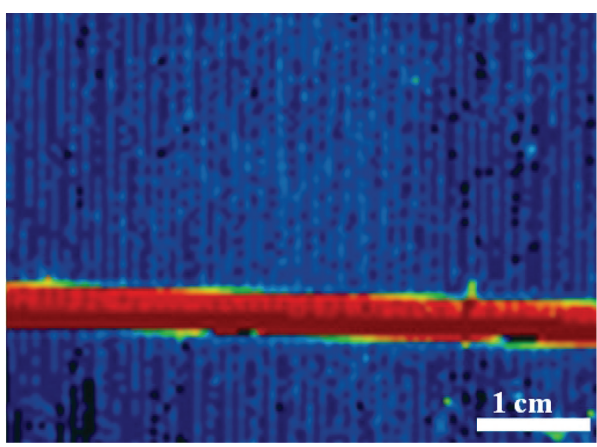

(a)

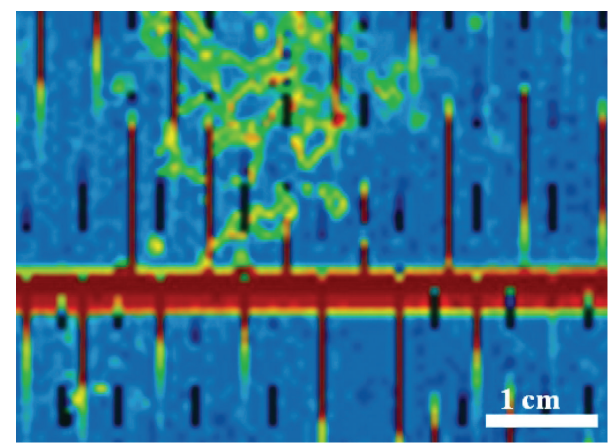

(b)

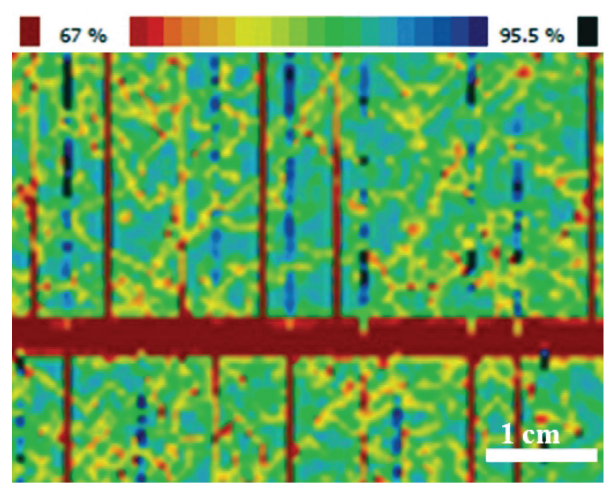

(c)

FIGURE 7: IQE distribution of solar cells fabricated on different substrates at $979 \mathrm{~nm}$ wavelength: ((a)-(c)) grades A-C, respectively. 


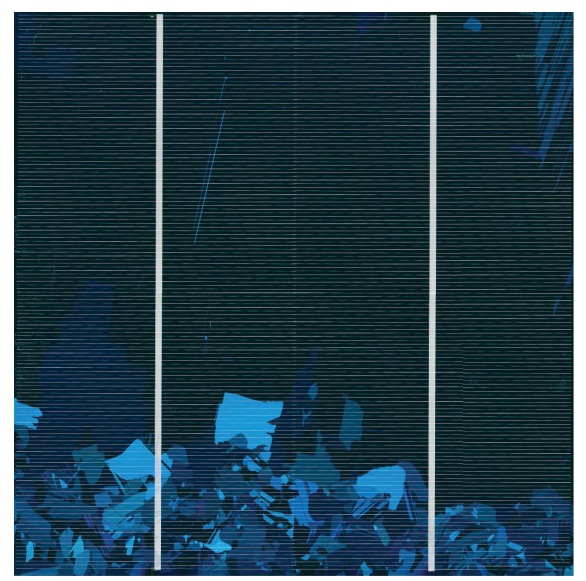

(a)

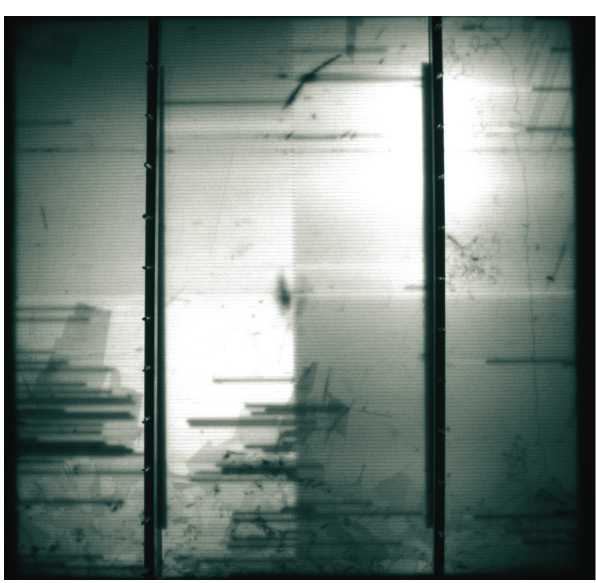

(b)

FIGURE 8: Optical (a) and EL (b) images of solar cells fabricated on wafers with hardly any sub-grain but with a small-grain band.

\section{Acknowledgments}

This work was supported by the National High Technology Research and Development Program of China (Grant no. 2011AA050515) and National Basic Research Program of China (Grant no. 2012CB934204).

\section{References}

[1] N. Asim, K. Sopian, S. Ahmadi et al., "A review on the role of materials science in solar cells," Renewable and Sustainable Energy Reviews, vol. 16, no. 8, pp. 5834-5847, 2012.

[2] D. Cunningham, A. Parr, J. Posbic, and B. Poulin, "Performance comparison between BP solar mono2 and traditional multicrystalline modules," in Proceedings of 23rd European Photovoltaic Solar Energy Conference and Exhibition(EUPVEC '08), pp. 2829-2833, Valencia, Spain, 2008.

[3] A. Jouini, D. Ponthenier, H. Lignier et al., "Improved multicrystalline silicon ingot crystal quality through seed growth for high efficiency solar cells," Progress in Photovoltaics: Research and Applications, vol. 20, no. 6, pp. 735-746, 2012.

[4] K. Nakajima, K. Morishita, R. Murai, and K. Kutsukake, "Growth of high-quality multicrystalline Si ingots using noncontact crucible method," Journal of Crystal Growth, vol. 355, no. 1, pp. 38-45, 2012.

[5] N. Stoddard, B. Wu, I. Witting et al., "Casting single crystal silicon: novel defect profiles from BP solar's mono ${ }^{2}$ wafers," Solid State Phenomena, vol. 131-133, pp. 1-8, 2007.

[6] V. Prajapati, E. Cornagliotti, R. Russell et al., "High efficiency industrial silicon solar cells on silicon Mono2 cast material using dielectric passivation and local BSF," in Proceeding of 24th European Photovoltaic Solar Energy Conference and Exhibition (EUPVSEC '09), pp. 1171-1174, Hamburg, Germany, 2009.

[7] X. Gu, X. Yu, K. Guo, L. Chen, D. Wang, and D. Yang, "Seedassisted cast quasi-single crystalline silicon for photovoltaic application: towards high efficiency and low cost silicon solar cells," Solar Energy Materials and Solar Cells, vol. 101, pp. 95-101, 2012.

[8] Y. Tsuchiya, H. Kusunoki, N. Miyazaki et al., "Correlation between carbon incorporation and defect formation in quasisingle crystalline silicon," in Proceedings of the 38th IEEE,
Photovoltaic Specialists Conference (PVSC '12), pp. 000297000301, 2012.

[9] Q. Yu, L. Liu, W. Ma, G. Zhong, and X. Huang, "Local design of the hot-zone in an industrial seeded directional solidification furnace for quasi-single crystalline silicon ingots," Journal of Crystal Growth, vol. 358, pp. 5-11, 2012.

[10] W. Ma, G. Zhong, L. Sun, Q. Yu, X. Huang, and L. Liu, "Influence of an insulation partition on a seeded directional solidification process for quasi-single crystalline silicon ingot for high-efficiency solar cells," Solar Energy Materials and Solar Cells, vol. 100, pp. 231-238, 2012.

[11] A. Black, J. Medina, A. Piñeiro, and E. Dieguez, "Optimizing seeded casting of mono-like silicon crystals through numerical simulation," Journal of Crystal Growth, vol. 353, no. 1, pp. 12-16, 2012.

[12] D. Hu, T. Zhang, L. He et al., "The characteristics of subgrains in the mono-like silicon crystals grown with directional solidification method," in Proceedings of the 38th IEEE, Photovoltaic Specialists Conference (PVSC '12), pp. 002735-002738, Austin, Tex, USA, 2012.

[13] B. Tjahjono, S. Wang, A. Sugianto et al., "Application of laser doped contact structure on multicrystalline solar cells," in Processding of 23rd European Photovoltaic Solar Energy Conference, pp. 1995-2000, Valencia, Spain, 2008.

[14] K. R. McIntosh, Lumps, humps, and bumps, Three detrimental effects in the current-voltage curve of silicon solar cells [Ph.D. thesis], Center of Excellence for Advanced Silicon Photovoltaics and Photonics, University of New South Wales, Sydney, Australia, 2001.

[15] T. Y. Wang, S. L. Hsu, C. C. Fei, K. M. Yei, W. C. Hsu, and C. W. Lan, "Grain control using spot cooling in multi-crystalline silicon crystal growth," Journal of Crystal Growth, vol. 311, no. 2, pp. 263-267, 2009.

[16] C. W. Lan, W. C. Lan, T. F. Lee et al., "Grain control in directional solidification of photovoltaic silicon," Journal of Crystal Growth, vol. 360, pp. 68-75, 2012.

[17] T. F. Li, K. M. Yeh, W. C. Hsu, and C. W. Lan, "High-quality multi-crystalline silicon (mc-Si) grown by directional solidification using notched crucibles," Journal of Crystal Growth, vol. 318, no. 1, pp. 219-223, 2011. 
[18] H. Sugimoto, K. Araki, M. Tajima et al., "Photoluminescence analysis of intragrain defects in multicrystalline silicon wafers for solar cells," Journal of Applied Physics, vol. 102, no. 5, Article ID 054506, 2007.

[19] W. Dimassi, L. Derbali, M. Bouaïcha, B. Bessaïs, and H. Ezzaouia, "Two-dimensional LBIC and Internal-QuantumEfficiency investigations of grooved grain boundaries in multicrystalline silicon solar cells," Solar Energy, vol. 85, no. 2, pp. 350-355, 2011.

[20] W. S. M. Brooks, S. J. C. Irvine, V. Barrioz, and A. J. Clayton, "Laser beam induced current measurements of $\mathrm{Cd}_{1-x} \mathrm{Zn}_{x} \mathrm{~S} / \mathrm{CdTe}$ solar cells," Solar Energy Materials and Solar Cells, vol. 101, pp. 26-31, 2012.

[21] S. Litvinenko, L. Ilchenko, A. Kaminski et al., "Investigation of the solar cell emitter quality by LBIC-like image techniques," Materials Science and Engineering: B, vol. 71, no. 1-3, pp. 238243,2000 . 

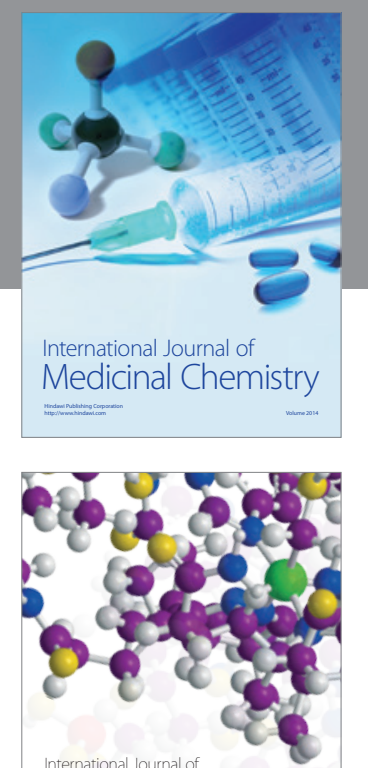

\section{Carbohydrate} Chemistry

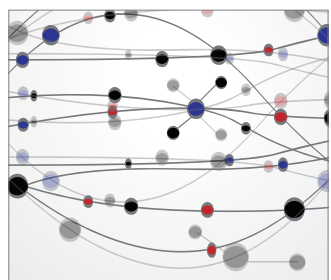

The Scientific World Journal
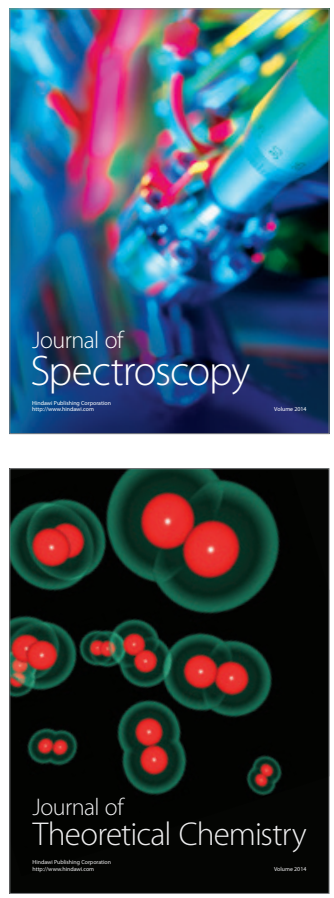
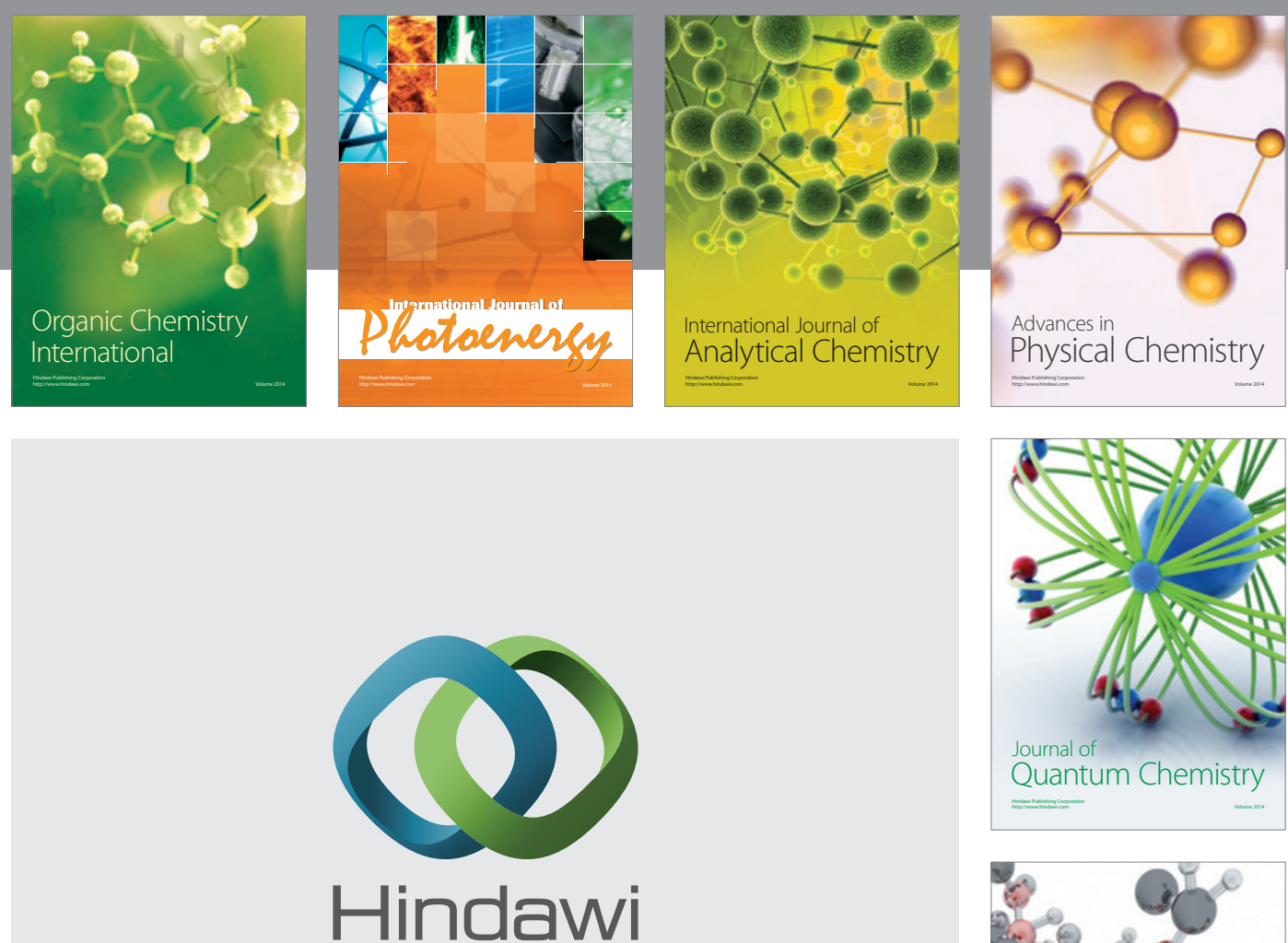

Submit your manuscripts at

http://www.hindawi.com

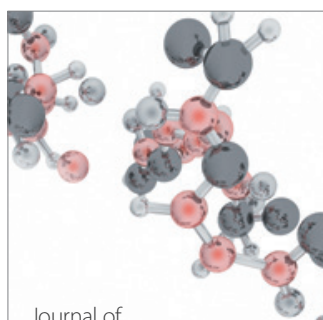

Analytical Methods

in Chemistry

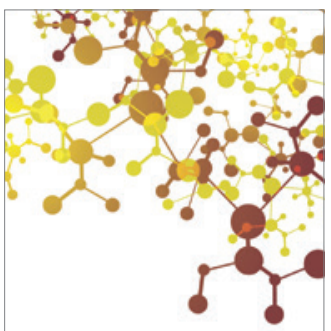

Journal of

Applied Chemistry

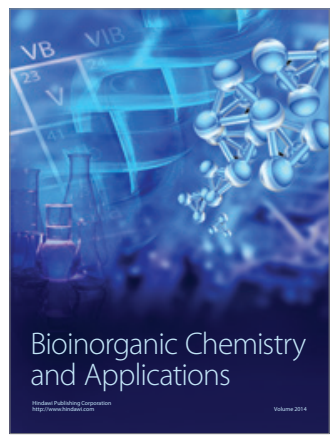

Inorganic Chemistry
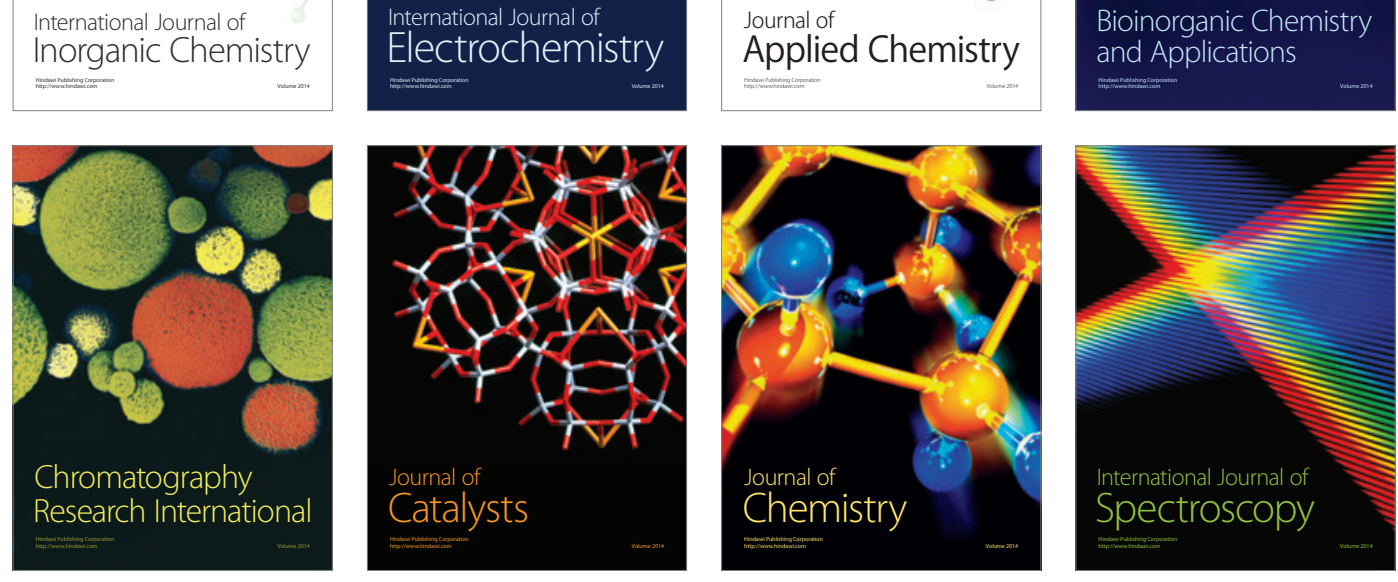